\title{
Involvement of the wrist and hand joints and tendons in an Egyptian systemic lupus erythematosus cohort
}

\author{
Omneya Mohamed-Ayman Abdel-Moniem ${ }^{1 *}$ (D) Sherine El-Sherif ${ }^{1}$, Mohamed Sami Barakat ${ }^{2}$, \\ Diaa Fahmy Mohasseb ${ }^{1}$ and Yousra Hisham Abdel-Fattah'
}

\begin{abstract}
Background: Systemic lupus erythematosus (SLE) patients often suffer hand function limitations even in the absence of symptoms related to joint or tendon disorders. Recent researches reported the presence of ultrasonographic (US) subclinical synovitis and tendon involvement in asymptomatic patients. We aimed to assess US patterns in SLE patients and determine their relationship with clinical assessment, disease activity and hand functional status using handheld dynamometry.
\end{abstract}

Results: We assessed 30 SLE patients (60 hands) using US; 21 (70\%) patient had synovial hypertrophy, 8 (26\%) showed a power Doppler (PD) activity, 6 (20\%) had erosions and 11 (36.6\%) had tendon US abnormality. Both patients with hand arthralgia/arthritis (symptomatic) and patients without arthralgia/arthritis (asymptomatic) had a statistically insignificant difference regarding the global synovitis score $(p=0.2)$ and disease activity $(p=0.3)$. However, the symptomatic group had a significantly increased number of joints with effusion $(p=0.04)$ and tendons involved $(p=0.04)$. The mean grip strength had a significant negative correlation with SLEDAI- $2 \mathrm{~K}$ score ( $\mathrm{rs}$ $=-0.4, p=0.02$ ) in the total patient group. In the asymptomatic group, a negative correlation was found between both mean grip ( $r s=-0.5, p=0.04$ ) and pinch strength ( $r s=-0.6, p=0.01$ ) with PD index, and mean pinch strength with the Jaccoud's arthropathy index ( $r s=-0.49, p=0.05$ ).

Conclusions: SLE patients may have higher subclinical synovitis, erosions and tendon involvement than expected, which may in turn reduce hand grip and pinch strength. Disease activity may also have a negative impact on the hand grip functional strength.

Keywords: Systemic lupus erythematosus, Musculoskeletal ultrasound, Grip dynamometry, Pinch dynamometry

\section{Key messages}

Systemic lupus erythematosus causes hand joint synovitis even in asymptomatic patients and reduces the hand functional strength.

\section{Background}

Systemic lupus erythematosus (SLE) is a complex, chronic multisystem autoimmune disease with a variable

\footnotetext{
* Correspondence: omneyamohamedayman@gmail.com

${ }^{1}$ Department of Physical Medicine, Rheumatology and Rehabilitation, Faculty of Medicine, Alexandria University, Alexandria, Egypt

Full list of author information is available at the end of the article
}

spectrum of manifestations, ranging from mild musculoskeletal (MSK) manifestations to potentially lifethreatening disease [1].

Despite that musculoskeletal (MSK) manifestations have long been thought of mild importance, even patients with no major organ affection raise complaints regarding major functional limitations attributed to MSK affection [2-4].

Up to $95 \%$ of patients experience arthralgia or arthritis during the course of their disease [5]. Traditionally, SLE arthritis is mainly localized to the small joints, and sometimes, hand deformities resemble rheumatoid 
arthritis (RA) [6]. Some patients experience limitations in their daily activity due to hand symptoms which may be their only reason for seeking healthcare facilities [3, 7].

Some authors have reported subclinical ultrasonographic (US) synovitis in asymptomatic SLE patients with a high percentage of tendon involvement [8-10]. Piga et al. in 2016 [11] found that baseline power Doppler (PD) synovitis score predicted MSK flare within 2 years from US examination. This may help physicians in detecting subclinical joint affection in the early phase of window of opportunity, optimizing medical treatment and suspecting Rhupus patients who display more aggressive MSK involvement.

Joints and tendons US scoring are not standardised yet in SLE [4]. The association between disease activity, MSK involvement, US findings and the functional status of the patient needs to be studied further to improve the patients' hand function necessary in performing their daily activities. Therefore, we assessed US patterns in SLE patients and determined their relationship with clinical assessment, disease activity and hand functional status using handheld dynamometry.

\section{Methods}

This cross-sectional study was conducted on 30 female patients with SLE fulfilling the Systemic Lupus Collaborating Clinics (SLICC) [12] criteria with age more than 18 and less than 65 years old. They were recruited from our Rheumatology and Rehabilitation outpatient clinic serving as a tertiary referral centre over a period of 1 year. Patients were excluded if they were proven to have hand osteoarthritis, previous hand trauma or surgery, and patients with hepatitis $\mathrm{C}$ virus-related arthritis, with inflammatory, metabolic or rheumatologic diseases. Patients with peripheral neuropathy, radiculopathy and nerve entrapment neuropathy known to affect the hand function were also excluded following history taking and neurological examination. It is noteworthy that we included 2 patients with Rhupus syndrome.

Patients with hand arthralgia/arthritis on examination date were categorised as symptomatic and those without as asymptomatic [13]. The clinical assessments were done including pain visual analogue scale (VAS) [14-16], verbal rating of the habitual intensity of manual labour [17], 28 tender joint count (TJC) and 28 swollen joint count (SJC) [18], presence or absence of hand tenosynovitis [19] and Jaccoud's arthropathy index (JAI) [20, 21]. Systemic Lupus Erythematosus Disease Activity Index 2000 (SLEDAI$2 \mathrm{~K})$ was calculated [22]. The mean maximal isometric hand grip and lateral pinch strength were measured using handheld grip and pinch dynamometery (Preston D-704607 PAT) and (Preston D-704608 PAT) respectively. Patients were seated on a chair with shoulders and wrist in neutral position, the elbow in $90^{\circ}$ flexion and the forearm parallel to the floor [23, 24]. They bilaterally pressed each dynamometer as hard as possible twice; the higher grip and pinch strength measurements of each hand were recorded and used to calculate the subject's mean maximal grip and pinch strength. Anti-cyclic citrullinated peptide (ACPA) antibodies were measured using Roche Elecsys immunoassay on Cobas e 411 automated analyser.

Thirty-eight age-matched healthy females were enrolled as a control group for dynamometry testing and intensity of manual labour rating.

Two assessors specialized in MSK US, blinded to the clinical status of the patients, screened the SLE patients according to the European League Against Rheumatism (EULAR) standardized imaging procedures in rheumatology [25] using a high-end US machine, RS80A Samsung Medison, Seoul, Korea, equipped with 3-16 MHz linear transducer (operating at $16 \mathrm{MHz}$ ) and PD settings (with avoidance of probe compression). They assessed the 2nd-5th metacarpophalangeal (MCP), 2nd-5th proximal interphalangeal (PIP), wrist joint (radiocarpal and midcarpal joints were assessed as a single unit and scanning was at the radio-lunate joint level) [26], the 2nd, 4th and 6th extensor tendon compartments, and the flexor tendons of the 3rd and 4th digits at the MCP level [27]. Synovial hypertrophy (SH) and PD activity scoring were done using the EULAR-Outcome Measures in Rheumatology (OMERACT) composite PDUS synovitis score (at the joint level) [26, 28]. For group comparison, we calculated the Global EULAR-OMERACT synovitis score (GLOESS) using the previous composite score and the PD index [29, 30]. Each joint was scored for bone erosion and effusion using a binary score (positive/negative), and the number of joints with effusion and erosions per patient was calculated [31]. The total number of pathological tendons or compartments (with grey scale (GS) changes or PD activity) per patient was calculated [27, 32]. It was scored using a semiquantitative score for GS where grade $0=$ normal; grade $1=$ minimal; grade 2 = moderate; and grade $3=$ severe and for PD where grade $0=$ no PD signal; grade $1=$ minimal (single focal peritendinous signal); grade $2=$ moderate (multifocal peritendinous signal); and grade $3=$ severe (diffuse peritendinous signal) [27]. We also referred to published consensus-based illustrative images [27]. All lesions detected by GS and PD were confirmed in 2 planes (longitudinal and transverse) [27].

\section{Statistical analysis}

Data was analysed by IBM SPSS 20 (Armonk, New York: IBM Corp). Student's $t$ test or Mann-Whitney test were 
applied for unpaired continuous variables. The chisquare test with Yates's correction for continuity or twotailed Fisher's exact test were applied when categorial variables/percentages were compared, ANOVA to compare between more than two groups and post hoc test (Tukey) for pairwise comparisons. For bivariate correlations, we used the Spearman rho correlation coefficient. The odds ratio with $95 \%$ CI was calculated. $P$ values $\leq$ 0.05 were considered significant.

\section{Results}

This study included 30 SLE patients with a mean age of $40.6 \pm 10.3$ years and median disease duration of 5.5 $(0.16-44)$ years. Twenty-eight patients $(93.3 \%)$ received corticosteroids (Cs); the remaining 2 patients (6.7\%) were asymptomatic. Hydroxychloroquine, azathioprine and methotrexate were received in 24 (80\%), 19 (63.3\%) and $6(20 \%)$ patients respectively.

Ninety percent of patients described MSK manifestations at some point across their illness even before establishing the disease diagnosis. History of arthralgia was present in $73.3 \%$, arthritis in $16.7 \%$ and morning stiffness (MS) in $40 \%$ of patients. Two patients (6.6\%) were ACPA positive; only 1 of the $2(50 \%)$ had sonographic erosions. Sixteen patients (53.3\%) had clinical tenosynovitis; 6 patients had unilateral hand involvement, while 10 patients were bilaterally involved. Fourteen patients (47\%) had joint deformities, of which 9 (64\%) had mild deforming arthropathy (JAI $\geq 1$ but $\leq 5$ ).

Sixteen patients $(53 \%)$ were clinically asymptomatic with a median disease duration of 5.5 (0.5-44) years, while $14(47 \%)$ were clinically symptomatic with a median disease duration of $5.5(0.16-18)$ years and a median VAS of $30(20-100)$ on examination date. There was no statistically significant difference between the 2 groups regarding disease duration $\left(U=110,{ }^{\mathrm{MC}} p=\right.$ 0.793). Table 1 demonstrates the age, intensity of manual labour and grip and pinch strength in the patient groups and the control group.

Table 2 compares between the symptomatic and asymptomatic patients regarding clinical and laboratory findings.

Twenty-one patients (70\%) showed US evidence of synovitis with at least 1 joint with $\mathrm{SH}$ with a grade $\geq 1$ whether active (PD activity) or inactive (no PD activity). It was found in $11(78.5 \%)$ out of 14 symptomatic patients and $10(62.5 \%)$ out of 16 asymptomatic. These findings were found to be asymmetric in distribution regardless of hand dominance, where 7 patients (33.3\%) had unilateral hand involvement. Eight patients (26.7\%) had at least 1 joint with a PD activity $\geq$ grade 1 . Eighteen patients $(60 \%)$ had $\geq 1$ joint effusion, and 6 patients (20\%) had erosions. The most frequent US abnormality in the screened joints (540) was $\mathrm{SH}$ in $13.3 \%$, while erosions were the least frequent in $1.1 \%$.

Eleven out of 30 patients (36.6\%) had US tendon/compartment pathology (25 (8\%) out of 300 tendons/compartments). Grade 1 GS was the commonest grading found in 19 (76\%) out of 25 pathologic tendons. The 4th extensor compartment was the most frequently affected by GS (7 (28\%) out of 25$)$; the 2 nd extensor compartment was the most frequently affected by PD (3 (50\%) out of 6 tendons with Doppler activity). Grade 1 PD activity was only recorded and limited to the extensor compartments. Table 2 compares between the symptomatic and asymptomatic groups regarding the different US findings. Figures 1 and 2 represent an example of asymptomatic and symptomatic patients respectively.

Patients were classified according to both joint deformity and US findings; 8 patients $(26.7 \%)$ had non-

Table 1 Distribution of the studied groups according to age, manual labour and grip and pinch dynamometry

\begin{tabular}{|c|c|c|c|c|c|c|c|c|}
\hline & \multicolumn{2}{|c|}{ Symptomatic (No. $=14)$} & \multicolumn{2}{|c|}{ Asymptomatic (No. = 16) } & \multicolumn{2}{|c|}{ Control $($ No. $=38)$} & \multirow[t]{2}{*}{ Test of sig. } & \multirow[t]{2}{*}{$p$} \\
\hline & No. & $\%$ & No. & $\%$ & No. & $\%$ & & \\
\hline Age (years) & \multicolumn{2}{|l|}{$41.57 \pm 6.05$} & \multicolumn{2}{|l|}{$39.88 \pm 13.11$} & \multicolumn{2}{|c|}{$36.32 \pm 12.63$} & $F=1.229$ & 0.299 \\
\hline \multicolumn{9}{|l|}{ Intensity of manual activity } \\
\hline Mild & 3 & 21.4 & 5 & 31.3 & 10 & 26.3 & \multirow[t]{4}{*}{$x^{2}=3.731$} & \multirow[t]{4}{*}{${ }^{M C} C_{p}=0.738$} \\
\hline Moderate & 5 & 35.7 & 3 & 18.8 & 9 & 23.7 & & \\
\hline Severe & 4 & 28.6 & 5 & 31.3 & 7 & 18.4 & & \\
\hline Very severe & 2 & 14.3 & 3 & 18.8 & 12 & 31.6 & & \\
\hline \multirow[t]{2}{*}{ Mean grip strength (lb) } & \multicolumn{2}{|l|}{$19.66 \pm 12.24$} & \multicolumn{2}{|l|}{$21.90 \pm 14$} & \multicolumn{2}{|c|}{$46.20 \pm 11.44$} & $F=36.09^{*}$ & $<0.001 *$ \\
\hline & \multicolumn{4}{|c|}{$p_{1}=0.870, \boldsymbol{p}_{\mathbf{2}}<0.001^{*}, \boldsymbol{p}_{\mathbf{3}}<0.001^{*}$} & & & & \\
\hline \multirow[t]{2}{*}{ Mean pinch strength (lb) } & \multicolumn{2}{|l|}{$8.57 \pm 4.01$} & \multicolumn{2}{|l|}{$10.18 \pm 3.15$} & \multicolumn{2}{|c|}{$13.88 \pm 2.34$} & $F=20.34^{*}$ & $<0.001 *$ \\
\hline & \multicolumn{6}{|c|}{$p_{1}=0.296, \boldsymbol{p}_{\mathbf{2}}<0.001^{*}, \boldsymbol{p}_{\mathbf{3}}<\mathbf{0 . 0 0 1 *}$} & & \\
\hline
\end{tabular}

Pairwise comparison between 2 groups was done using post hoc test (Tukey)

$X^{2}$ chi-square test; MC Monte Carlo; F F for ANOVA test; $p p$ value for comparing between the studied groups, significance at $p<0.05 ; p_{1} p$ value for comparing between symptomatic and asymptomatic; $p_{2} p$ value for comparing between symptomatic and control; $p_{3} p$ value for comparing between asymptomatic and control; No. number; $\%$ percent; $L b$ pound 
Table 2 Comparison between the symptomatic and asymptomatic patients regarding the different parameters

\begin{tabular}{|c|c|c|c|c|}
\hline & Symptomatic (no. = 14) & Asymptomatic (no. $=16)$ & Test of sig. & $p$ \\
\hline${\text { Cumulative dose } \mathrm{Cs} / \text { gram }^{a}}^{a}$ & $10.58(0.3-109.3)$ & $7.5(0-70.2)$ & $U=92.0$ & 0.423 \\
\hline TJC (0-28) & $7.5(0-25)$ & $0.5(0-4)$ & $U=13.50$ & $<0.001^{\mathrm{a}}$ \\
\hline SJC (0-28) & $3.5(0-13)$ & $1(0-6)$ & $U=53.0$ & $0.013^{\mathrm{a}}$ \\
\hline JAI & $0(0-4)$ & $2(0-12)$ & $U=73.50$ & 0.110 \\
\hline SLEDAI-2K score & $8(1-28)$ & $6.5(0-42)$ & $U=87.0$ & 0.313 \\
\hline SLEDAI MSK (0/4) & $0(0-4)$ & $0(0-4)$ & $U=85.0$ & 0.275 \\
\hline Anti-dsDNA level & $17.7(14.5-36.1)$ & $31.2(14.3-389)$ & $U=60.50$ & $0.031^{\mathrm{a}}$ \\
\hline C3 level & $117.43 \pm 19.62$ & $101.19 \pm 31.04$ & $t=1.684$ & 0.103 \\
\hline C4 level & $27.27 \pm 6.69$ & $19.63 \pm 9.32$ & $t=2.546$ & $0.017^{\mathrm{a}}$ \\
\hline ACPA level & $7.55(5.7-268)$ & $8.15(4.3-12.1)$ & $U=111.50$ & 0.984 \\
\hline GLOESS & $2(0-16)$ & $1(0-17)$ & $U=81.500$ & 0.208 \\
\hline No. of joints with effusion/US & $1.5(0-6)$ & $0(0-5)$ & $U=64.50$ & $0.047^{\mathrm{a}}$ \\
\hline No. of joints with erosions/US & $0(0-2)$ & $0(0-2)$ & $U=103.0$ & 0.728 \\
\hline No. of joints with SH/US & $2(0-9)$ & $1(0-9)$ & $U=80.50$ & 0.193 \\
\hline PD index/US & $0(0-2)$ & $0(0-2)$ & $U=108.0$ & 0.443 \\
\hline No. of pathologic tendons/US & $1(0-5)$ & $0(0-3)$ & $U=64.0$ & $0.047^{\mathrm{a}}$ \\
\hline
\end{tabular}

$t$ Student $t$ test; $U$ Mann-Whitney; $p p$ value for comparing between the studied groups, significance at $p<0.05$; $C s$ corticosteroids; TJC tender joint count; SJC swollen joint count; JAI Jaccoud's arthropathy index; SLEDAI-2K systemic lupus erythematosus disease activity index 2000; SLEDAI MSK musculoskeletal SLEDAl; Anti-dsDNA anti-double-stranded deoxyribonucleic acid; C3 and C4 serum complement 3 and 4; ACPA anti-citrullinated protein antibodies; GLOESS Global EULAROMERACT synovitis score; US ultrasound, No. number; SH synovial hypertrophy; $P D$ power Doppler

${ }^{\text {a } T w o ~ a s y m p t o m a t i c ~ p a t i e n t s ~ d i d ~ n o t ~ r e c e i v e ~ c o r t i c o s t e r o i d s ~(n o . ~}=14$ )

deforming non-erosive arthritis, 3 (10\%) non-deforming erosive arthritis, $9(30 \%)$ mild deforming arthropathy, 1 (3.3\%) deforming erosive arthritis (Rhupus patient), 2 (13.3\%) Jaccoud's arthropathy and 5 (16.7\%) had normal joints. Thus, SLE joint involvement in our cohort was 83.3\%.

In the total patient population, VAS showed a positive correlation with the number of pathological tendons (rs $=0.48, p=0.006)$, duration of MS ( $\mathrm{rs}=0.5, p=0.04$ ) and TJC ( $\mathrm{rs}=0.78, p<0.0001$ ). JAI had a negative correlation with the intensity of manual labour (rs = $0.37, p=0.04)$ and a positive correlation with the disease duration ( $\mathrm{rs}=0.44, p=0.015$ ). The mean grip strength had a negative correlation with the age $(\mathrm{rs}=-0.5, p=$ 0.003 ) and SLEDAI-2K score ( $\mathrm{rs}=-0.4, p=0.02)$. The mean pinch strength had a negative correlation with the age and the SJC ( $\mathrm{rs}=-0.45, p=0.01$ ). The GLOESS had a significant correlation with the cumulative dose of Cs intake ( $\mathrm{rs}=0.39, p=0.05)$. The PD index had a positive correlation with age ( $\mathrm{rs}=0.48, p=0.006)$ and anti-

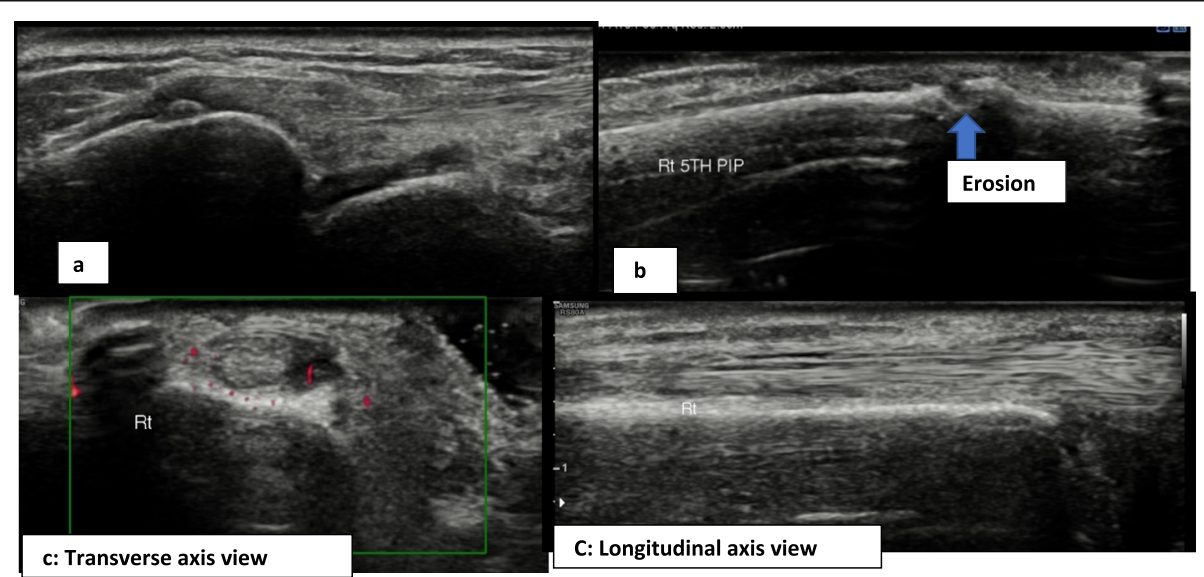

Fig. 1 A 57 years old asymptomatic patient, ACPA negative, anti-dsDNA positive and SLEDAI-2K score of 23. a Left radio-lunate joint with grade 2 SH and effusion. b Right PIP with grade 2 SH and erosion. c Right 6th extensor compartment grade 2 tenosynovitis with grade 1 PD activity 


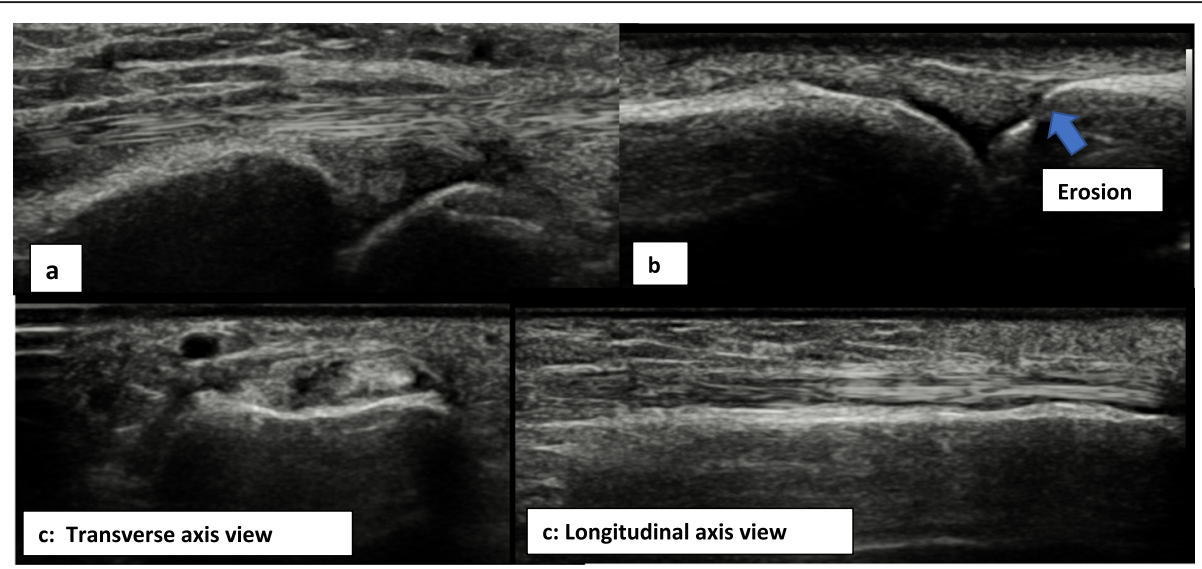

Fig. 2 A 43 years old symptomatic patient, ACPA and anti-dsDNA negative and SLEDAI-2k score of 16. a Right radio-lunate joint with grade 2 SH. b Right 3rd MCP with erosion. $\mathbf{c}$ Left 6th extensor compartment grade 2 tenosynovitis

dsDNA level ( $\mathrm{rs}=0.4, p=0.02)$ but had a negative insignificant correlation with the cumulative dose of Cs intake ( $\mathrm{rs}=-0.029, p=0.88$ ).

In the asymptomatic group, JAI showed a positive correlation with the number of joints with sonographic effusion ( $\mathrm{rs}=0.67, p=0.004$ ) and a negative correlation with the mean pinch strength ( $\mathrm{rs}=-0.49, p=0.050$ ). The PD index had a negative correlation with both the mean maximal grip and pinch strength $(\mathrm{rs}=-0.5, p=$ 0.04 and $\mathrm{rs}=-0.6, p=0.01$ respectively). The number of joints with erosions correlated with the number of pathological tendons/ compartments ( $\mathrm{rs}=0.51, p=$ 0.04).

In the symptomatic group, the number of joints with erosions correlated with SJC ( $\mathrm{rs}=0.61, p=0.02)$.

\section{Discussion}

\section{The magnitude of MSK involvement}

In this study, different degrees of joint involvement have been shown to be underestimated in SLE patients, where 83.3\% of patients had either clinical or sonographic joint involvement. Both symptomatic and asymptomatic patients had comparable US scores with no significant difference between them. Ten (62.5\%) out of 16 asymptomatic patients had a sonographic evidence of synovitis. This finding has recently been described in the literature by "subclinical synovitis" $[8,9,13,33]$. No significant difference was found between both patient groups regarding PD index probably because they had comparable cumulative dose of Cs intake. Ruano et al. [8] suggested that the high prevalence of steroid use among the SLE population could reduce the global inflammatory burden and result in lower prevalence and grading of the US PD findings.

In addition, 16 patients displayed clinical tenosynovitis, while sonographic tendon/compartment involvement was only found in 11 patients. The discrepancy between the clinical and sonographic data has been attributed in literature to the presence of pain related to depression, fatigue and neuropathic pain with central sensitization or overlap with fibromyalgia leading to an exaggerated symptomatology [34, 35]. Lins and Santiago [36] and Mosca et al. [37] agreed that US cannot be used as a confirmatory diagnostic method of symptomatology since not all clinical changes necessarily correspond to anatomic lesion in US (synovitis/tenosynovitis).

Despite the magnitude of joint and tendon involvement, low GS and PD scoring was the most frequent sonographic finding in both joints and tendons, explaining the subclinical presentation. It seems that despite the devastating major organ damage in SLE, MSK affection is the least worrisome but not the least frequent. The weight of SLE-related joint damage in comparison with other organ damage is 1 out of 47 according to the SLICC/American College of Rheumatology Damage Index [38]. However, arthralgia is as frequent as $85-94 \%[39,40]$. In our study, 21 patients $(33.3 \%)$ had unilateral hand joint involvement which disagrees with the previous understanding that SLE displays a symmetrical joint affection [5, 21].

Erosions were the least frequent sonographic abnormality, and they were all detected in the dominant hand suggesting a mechanical causative factor. This could be supported by the absence of localized joint tenderness at erosion sites and its correlation with the number of tendons with sonographic abnormality. Inflamed tendons, lax ligaments, and pulleys cause mechanical disadvantage leading to erosion formation. Van Vugt et al. [41] suggested that bone erosions in SLE, other than Rhupus, are caused by friction rub of the overlying inflamed tendons or ligaments. The clinical impact of erosions remains undetermined since no correlations were found with either deformities (JAI) or hand strength. 


\section{Are there limitations in hand function?}

Grip and pinch strength were significantly impaired in both asymptomatic and symptomatic patients compared to the control group. The mean grip strength had a significant negative correlation with SLEDAI-2K score denoting that disease activity is an important determinant of the grip strength necessary in performing activities of daily living. In addition, we also found a negative correlation between the PD index (marker of active synovitis) with both mean grip and pinch strength in the asymptomatic group. In a study of RA patients, Dedeoğlu et al. [42] found a similar correlation between the disease activity and both grip and pinch strength. In addition, the lateral pinch strength negatively correlated with JAI, while the grip did not. The pinch requires more precision and isolation of the thumb and the index, making it more liable to the extent of joint deformity and active synovitis. Vlieland et al. [43] suggested that flexion attitude or deformity of the thumb and MCP subluxation consistently attribute to impaired hand function in RA patients.

It seems that the deficit in grip strength due to joint inflammation or deformity in SLE was compensated by the unaffected surrounding joints contributing to the grip strength. However, upon pinch strength testing, the deficit was unmasked.

\section{What determines deformities?}

Forty-seven percent of the studied patients had various grades of deformities and JAI positively correlated with disease duration, which is in accordance with the published literature $[41,44,45]$. Also, a significant negative correlation was found with intensity of manual labour; the more intense the labour, the less liability for deformity formation. The deformity in SLE seems to be the consequence of ligament laxity combined with muscle imbalance, rather than the destructive effect of synovitis as in RA [41]. It seems that intense manual work guards against muscle wasting with subsequent deformity prevention and preserves joint mobility.

In the asymptomatic group, JAI correlated with the number of joints with sonographic effusion while it did not correlate with the GLOESS, PD index or tendons pathology. We also suggest that joint effusion is attributed to the mechanical disadvantage caused by the deformities rather than an intrinsic joint pathology. This fact is supported by the recent OMERACT criteria which disregarded effusion as a sign of synovitis [28].

\section{What caused hand arthralgia?}

The VAS did not correlate with either the GLOESS or the joints PD index, while it correlated with the number of pathological tendons. Torrente-Segarra et al. [13] found a higher frequency of tenosynovitis (39.2\%) in SLE hand arthralgia group compared to synovial hypertrophy (25\%) or active arthritis (14.2\%). In addition, Doppler activity was significantly higher in their arthralgia group compared to the nonarthralgia group, which contradicts our findings, probably due to the summation of the tendons and joints Doppler status.

\section{Limitations}

Prospective longitudinal studies are necessary to explore the outcomes of subclinical joint affection and silent erosions. In addition, the impact of hand isometric strengthening exercises and patient education programs concerned with joint protection on grip function and deformity prevention needs to be investigated.

\section{Conclusion}

SLE patients may have higher subclinical synovitis, erosions and tendon involvement than expected, which may in turn reduce hand grip and pinch strength. Disease activity may also have a negative impact on the hand grip functional strength. The asymmetric pattern of US findings irrespective of hand dominance suggests the importance of performing bilateral joints screening, with priority to the wrist and MCPs.

\section{Abbreviations \\ ACPA: Anti-cyclic citrullinated peptide/proteins; Anti-dsDNA: Anti-double- stranded deoxyribonucleic acid; ANOVA: Analysis of variance; C3 and C4: Serum complement 3 and 4; Cs: Corticosteroids; EULAR: European League Against Rheumatism; GLOESS: Global European League Against Rheumatism Outcome Measures in Rheumatology synovitis score; GS: Grey scale; JAl: Jaccoud's arthropathy index; Ib: pound; MC: Monte Carlo; MCP: Metacarpophalangeal; MSK: Musculoskeletal; No.: Number; OMERACT: Outcome Measures in Rheumatology; PD: Power Doppler; PIP: Proximal interphalangeal; RA: Rheumatoid arthritis; rs: Spearman rho correlation coefficient; SH: Synovial hypertrophy; SJC: Swollen joint count; SLE: Systemic lupus erythematosus; SLEDAI-2K: Systemic Lupus \\ Erythematosus Disease Activity Index 2000; SLEDAI MSK: Musculoskeletal SLEDAI; SLICC: Systemic Lupus Collaborating Clinics; SPSS: Statistical Package for the Social Sciences; $t$ : Student $t$ test; TJC: Tender joint count; U: Mann- Whitney; US: Ultrasonographic; VAS: Visual analogue scale}

\section{Acknowledgements}

We would like to express our gratitude towards Alexandria Regional Centre for Women's Health where our patients' sonographic assessment took place. The centre did not provide any funds or grants to this research.

\section{Authors' contributions}

AM O contributed to the clinical assessment, interpretation of data and a major contributor in writing this manuscript. ES S contributed to the interpretation of data and work edit. B M performed the sonographic assessment. M D put the idea and design of the work. AF Y performed the sonographic assessment, interpretation of data and work edit. All authors read and approved the final manuscript.

Funding

The authors declare that it is a non-funded research.

Availability of data and materials

All data and materials are available upon request. 


\section{Ethics approval and consent to participate}

The study was approved by the local ethics committee of the Faculty of Medicine, Alexandria University (approval number 0201198) and performed according to the Declaration of Helsinki. A written consent was obtained from all participants before enrolment in the study.

\section{Consent for publication}

A consent for publication was obtained from all participants.

\section{Competing interests}

The authors declare that they have no competing interests.

\section{Author details}

'Department of Physical Medicine, Rheumatology and Rehabilitation, Faculty of Medicine, Alexandria University, Alexandria, Egypt. ${ }^{2}$ Diagnostic Radiology, Faculty of Medicine, Alexandria University, Alexandria, Egypt.

\section{Received: 28 April 2020 Accepted: 2 July 2020}

Published online: 01 December 2020

\section{References}

1. Zayat AS, Yusof MYM, Wakefield RJ, et al (2016) The role of ultrasound in assessing musculoskeletal symptoms of systemic lupus erythematosus: a systematic literature review. Rheumatol (United Kingdom) 55:485-494. https://doi.org/https://doi.org/10.1093/rheumatology/kev343

2. Drenkard C, Bao G, Dennis G, et al (2014) Burden of systemic lupus erythematosus on employment and work productivity: data from a large cohort in the southeastern United States. Arthritis Care Res 66:878-887. https://doi.org/https://doi.org/10.1002/acr.22245

3. Malcus Johnsson P, Sandqvist G, Nilsson JA, et al (2015) Hand function and performance of daily activities in systemic lupus erythematosus: a clinical study. Lupus 24:827-834. https://doi.org/https://doi.org/10.1177/ 0961203314565690

4. Di Matteo A, Isidori M, Corradini D, et al (2019) Ultrasound in the assessment of musculoskeletal involvement in systemic lupus erythematosus: state of the art and perspectives. Lupus 28:583-590. https:// doi.org/https://doi.org/10.1177/0961203319834671

5. Grossman JM (2009) Lupus arthritis. Best Pract Res Clin Rheumatol 23:495506. https://doi.org/https://doi.org/10.1016/j.berh.2009.04.003

6. Pipili C, Sfritzeri A, Cholongitas E (2008) Deforming arthropathy in systemic lupus erythematosus. Eur J Intern Med 19:482-487. https://doi.org/https:// doi.org/10.1016/j.ejim.2008.01.017

7. Wright S, Filippucci E, Grassi W, et al (2006) Hand arthritis in systemic lupus erythematosus: an ultrasound pictorial essay. Lupus 15:501-506. https://doi. org/https://doi.org/10.1191/0961203306lu2340oa

8. Ruano CA, Malheiro R, Oliveira JF, et al (2017) Ultrasound detects subclinical joint inflammation in the hands and wrists of patients with systemic lupus erythematosus without musculoskeletal symptoms. Lupus Sci Med 4:1-8. https://doi.org/https://doi.org/10.1136/lupus-2016-000184

9. Salliot C, Denis A, Dernis E, et al (2018) Ultrasonography and detection of subclinical joints and tendons involvements in systemic lupus erythematosus (SLE) patients: a cross-sectional multicenter study. Jt Bone Spine 85:741-745. https://doi.org/https://doi.org/10.1016/j.jbspin.2018.01.013

10. Di Matteo A, De Angelis R, Cipolletta E, et al (2018) Systemic lupus erythematosus arthropathy: the sonographic perspective. Lupus 27:794-801. https://doi.org/https://doi.org/10.1177/0961203317747716

11. Piga M, Gabba A, Congia M, et al (2016) Predictors of musculoskeletal flares and Jaccoud's arthropathy in patients with systemic lupus erythematosus: a 5-year prospective study. Semin Arthritis Rheum 46:217-224. https://doi.org/ https://doi.org/10.1016/j.semarthrit.2016.04.005

12. Petri M, Orbai AM, Alarcõn GS, et al (2012) Derivation and validation of the systemic lupus international collaborating clinics classification criteria for systemic lupus erythematosus. Arthritis Rheum 64:2677-2686. https://doi. org/https://doi.org/10.1002/art.34473

13. Torrente-Segarra V, Lisbona MP, Rotés-Sala D et al (2013) Hand and wrist arthralgia in systemic lupus erythematosus is associated to ultrasonographic abnormalities. Jt. Bone Spine 80:402-406

14. Van-Riel P, Gestel A SD (2000) Assessing disease course: rating scales for pain and global disease activity. In: EULAR handbook of clinical assessment in rheumatoid arthritis. Van Zuiden Communications, Nijmegen, the Netherlands, pp 22-23
15. Jensen MP, Karoly P, Braver S (1986) The measurement of clinical pain intensity: a comparison of six methods. Pain 27:117-126. https://doi.org/ https://doi.org/10.1016/0304-3959(86)90228-9

16. Ferraz MB, Quaresma MR, Aquino LRL et al (1990) Reliability of pain scales in the assessment of literate and illiterate patients with rheumatoid arthritis. J Rheumatol 17:1022-1024

17. Van-Riel PLCM, Van-Gestel AMSD (2000) Assessing disease course: assessment technique. In: EULAR handbook of clinical assessment in rheumatoid arthritis. Van Zuiden Communications, Nijmegen, the Netherlands, pp 13-20

18. Fuchs HA, Brooks RH, Callahan LF, Pincus T (1989) A simplified twentyeight-joint quantitative articular index in rheumatoid arthritis. Arthritis Rheum 32:531-537. https://doi.org/https://doi.org/10.1002/anr.1780320504

19. Harrington JM, Carter JT, Birrell L, Gompertz D (1998) Surveillance case definitions for work related upper limb pain syndromes. Occup Environ Med 55:264-271. https://doi.org/https://doi.org/10.1136/oem.55.4.264

20. Spronk PE, Ter Borg EJ, Kallenberg CGM (1992) Patients with systemic lupus erythematosus and Jaccoud's arthropathy: a clinical subset with an increased C reactive protein response? Ann Rheum Dis 51:358-361. https:// doi.org/https://doi.org/10.1136/ard.51.3.358

21. Ball EMA, Bell AL (2012) Lupus arthritis-do we have a clinically useful classification? Rheumatology 51:771-779. https://doi.org/https://doi.org/10. 1093/rheumatology/ker381

22. Gladman DD, Ibañez D, Urowltz MB (2002) Systemic lupus erythematosus disease activity index 2000. J Rheumatol 40:733

23. Stockton KA, Wrigley T V., Mengersen KA, et al (2011) Test-retest reliability of hand-held dynamometry and functional tests in systemic lupus erythematosus. Lupus 20:144-150. https://doi.org/https://doi.org/10.1177/ 0961203310388448

24. van der Giesen FJ, Nelissen RGHH, Rozing PM, et al (2007) A multidisciplinary hand clinic for patients with rheumatic diseases: a pilot study. J Hand Ther 20:251-261. https://doi.org/https://doi.org/10.1197/j.jht. 2007.04.004

25. Möller I, Janta I, Backhaus M, et al (2017) The 2017 EULAR standardised procedures for ultrasound imaging in rheumatology. Ann Rheum Dis 76: 1974-1979. https://doi.org/https://doi.org/10.1136/annrheumdis-2017211585

26. Terslev L, Naredo E, Aegerter P, et al (2017) Scoring ultrasound synovitis in rheumatoid arthritis: a EULAR-OMERACT ultrasound taskforce-part 2: reliability and application to multiple joints of a standardised consensusbased scoring system. RMD Open 3:e000427. https://doi.org/https://doi.org/ 10.1136/rmdopen-2016-000427

27. Naredo E, D'Agostino MA, Wakefield RJ, et al (2013) Reliability of a consensus-based ultrasound score for tenosynovitis in rheumatoid arthritis. Ann Rheum Dis 72:1328-1334. https://doi.org/https://doi.org/10.1136/ annrheumdis-2012-202092

28. D'Agostino MA, Terslev L, Aegerter $\mathrm{P}$, et al (2017) Scoring ultrasound synovitis in rheumatoid arthritis: a EULAR-OMERACT ultrasound taskforce part 1: definition and development of a standardised, consensus-based scoring system. RMD Open 3:e000428. https://doi.org/https://doi.org/10. 1136/rmdopen-2016-000428

29. D'Agostino M, Wakefield R, Berner-Hammer H, Vittecoq O, Filippou G, Balint $P$ et al (2016) Value of ultrasonography as a marker of early response to abatacept in patients with rheumatoid arthritis and an inadequate response to methotrexate: results from the APPRAISE study. Ann Rheum Dis 75:17631769. https://doi.org/https://doi.org/10.1136/annrheumdis-2015-207709

30. Filer A, De Pablo P, Allen G, et al (2011) Utility of ultrasound joint counts in the prediction of rheumatoid arthritis in patients with very early synovitis. Ann Rheum Dis 70:500-507. https://doi.org/https://doi.org/10.1136/ard.2010. 131573

31. Backhaus M, Burmester GR, Gerber T, et al (2001) Guidelines for musculoskeletal ultrasound in rheumatology. Ann Rheum Dis 60:641-649. https://doi.org/https://doi.org/10.1136/ard.60.7.641

32. Gabba A, Piga M, Vacca A, et al (2012) Joint and tendon involvement in systemic lupus erythematosus: an ultrasound study of hands and wrists in 108 patients. Rheumatol (United Kingdom) 51:2278-2285. https://doi.org/ https://doi.org/10.1093/rheumatology/kes226

33. Zayat AS, Mahmoud K, Md Yusof MY, et al (2019) Defining inflammatory musculoskeletal manifestations in systemic lupus erythematosus. Rheumatol (United Kingdom) 58:304-312. https://doi.org/https://doi.org/10.1093/ rheumatology/key277 
34. Di Franco M, Guzzo MP, Spinelli FR, et al (2014) Pain and systemic lupus erythematosus. Reumatismo 66:33-38. https://doi.org/https://doi.org/10. 4081/reumatismo.2014.762

35. Friend R, Bennett RM (2011) Distinguishing fibromyalgia from rheumatoid arthritis and systemic lupus in clinical questionnaires: an analysis of the revised fibromyalgia impact questionnaire (FIQR) and its variant, the symptom impact questionnaire (SIQR), along with pain locations. Arthritis Res Ther 13:R58. https://doi.org/https://doi.org/10.1186/ar3311

36. Lins CF, Santiago MB (2015) Ultrasound evaluation of joints in systemic lupus erythematosus: a systematic review. Eur Radiol 25:2688-2692. https:// doi.org/https://doi.org/10.1007/s00330-015-3670-y

37. Mosca M, Tani C, Carli L, et al (2015) The role of imaging in the evaluation of joint involvement in 102 consecutive patients with systemic lupus erythematosus. Autoimmun Rev 14:10-15. https://doi.org/https://doi.org/10. 1016/j.autrev.2014.08.007

38. Gladman D, Ginzler E, Goldsmith C, et al (1996) The development and initial validation of the systemic lupus international collaborating clinics/American College of Rheumatology damage index for systemic lupus erythematosus. Arthritis Rheum 39:363-369. https://doi.org/https://doi.org/10.1002/art. 1780390303

39. Leuchten N, Milke B, Winkler-Rohlfing B, et al (2018) Early symptoms of systemic lupus erythematosus (SLE) recalled by 339 SLE patients. Lupus 27 1431-1436. https://doi.org/https://doi.org/10.1177/0961203318776093

40. Worrall JG, Snaith ML, Batchelor JR, Isenberg DA (1990) SLE: a rheumatological view. Analysis of the clinical features, serology and immunogenetics of 100 SLE patients during long-term follow-up. QJM 74: 319-330. https://doi.org/https://doi.org/10.1093/oxfordjournals.qjmed. a068440

41. Van Vugt RM, Derksen RHWM, Kater L, Bijlsma JWJ (1998) Deforming arthropathy or lupus and rhupus hands in systemic lupus erythematosus. Ann Rheum Dis 57:540-544. https://doi.org/https://doi.org/10.1136/ard.57.9. 540

42. Dedeoğlu M, Gafuroğlu Ü, Yilmaz Ö, Bodur H (2013) Relationship between hand grip and pinch strengths and disease activity, articular damage, pain, and disability in patients with rheumatoid arthritis. Turkish J Rheumatol 28: 69-77. https://doi.org/https://doi.org/10.5606/tjr.2013.2742

43. Vliet Vlieland TPM, Van Der Wijk TP, Jolie IMM et al (1996) Determinants of hand function in patients with rheumatoid arthritis. J Rheumatol 28:835-840

44. Johnsson PM, Sandqvist G, Bengtsson A, Nived O (2008) Hand function and performance of daily activities in systemic lupus erythematosus. Arthritis Care Res 59:1432-1438. https://doi.org/10.1002/art.24108

45. Dray GJ (1989) The hand in systemic lupus erythematosus. Hand Clin 5:145155

\section{Publisher's Note}

Springer Nature remains neutral with regard to jurisdictional claims in published maps and institutional affiliations.

\section{Submit your manuscript to a SpringerOpen ${ }^{\circ}$ journal and benefit from:}

- Convenient online submission

- Rigorous peer review

- Open access: articles freely available online

- High visibility within the field

- Retaining the copyright to your article

Submit your next manuscript at $\boldsymbol{\nabla}$ springeropen.com 